\title{
ANÁLISE NÃO LINEAR DE SISTEMAS TRELIÇADOS ESPACIAIS UTILIZADOS PARA ESCORAMENTOS DE ESTRUTURAS DE AÇO E MISTAS
}

\author{
Miguel H. O. Costa ${ }^{1}$; José G. S. da Silva ${ }^{2}$; Luciano R. O. de Lima ${ }^{2}$ \\ ${ }^{1}$ Programa de Pós-Graduação em Engenharia Civil, PGECIV, Universidade do Estado do Rio \\ de Janeiro, UERJ (miguelh.o@gmail.com)
}

${ }^{2}$ Departamento de Estruturas e Fundações, Universidade do Estado do Rio de Janeiro, UERJ

\begin{abstract}
Resumo. Atualmente, a utilização de estruturas treliçadas para o escoramento de elementos estruturais de concreto e aço é considerada por muitos engenheiros, uma solução necessária para os problemas da engenharia estrutural. Todavia, mudanças de atitudes dentro da construção civil e uma transição global para o desenvolvimento e a produtividade na construção alheia a redução dos custos, tem seguramente provocado um aumento no uso de treliças com maior capacidade de carga sendo tão leves quanto às treliças convencionais. A definição das ações estáticas atuantes sobre os modelos estruturais foi feita com base em resultados reais, os quais levam em conta os efeitos de resistência para carregamentos estáticos. A análise fundamenta-se na modelagem computacional dos sistemas estruturais, através do Método dos Elementos Finitos (MEF). São empregadas técnicas usuais de discretização, por meio do emprego do programa ANSYS [1]. No presente modelo numérico-computacional, as estruturas em aço são simuladas por elementos finitos tridimensionais, onde são considerados os efeitos de flexão e torção. As análises realizadas são do tipo linear elástica e não linear geométrica e física. Os resultados obtidos são comparados com os limites recomendados em normas de projeto e sua utilização no mercado, no que tange aos carregamentos estáticos.
\end{abstract}

Palavras-chave: Escoramentos, Modelagem computacional, Comportamento estrutural.

\section{INTRODUÇÃO}

No âmbito da construção civil, a utilização de estruturas treliçadas para o escoramento de elementos estruturais permanentes e provisórios vem sendo escolhida como opção cada vez mais difundida, diante da necessidade de desenvolvimento técnico e, ainda, objetivando a redução de custos e prazos. Este procedimento tem gerado sistemas estruturais com a capacidade de utilização em grandes vãos livres, elevada capacidade de resistência aos carregamentos estáticos das estruturas escoradas, tão leves quanto às treliças convencionais.

Além do critério economia, outros fatores que influenciam decisivamente para a escolha do sistema treliçado como solução estrutural para escoramento dos elementos estruturais diz respeito à liberdade arquitetônica, pois permitem grandes vãos e, também, a simplificação 
na execução da obra, em termos de formas e escoramentos, quando aplicado em sistemas estruturais de grande porte.

Apesar das vantagens acima apresentadas, como em qualquer outra escolha de sistema construtivo, alguns cuidados devem ser tomados para que o sistema treliçado apresente um comportamento adequado. Deste modo, este trabalho de pesquisa objetiva apresentar um estudo do comportamento estático de sistemas de escoramentos treliçados, a partir do desenvolvimento de modelos numérico-computacionais que simulem este comportamento da forma mais adequada possível, de acordo com a resposta de modelos estruturais reais e sua utilização no mercado.

Assim sendo, ao longo desta investigação desenvolve-se uma análise paramétrica, onde o objetivo central é obter a resposta deste sistema estrutural em termos de resistência à flexão, esforços normais, tensões atuantes e deslocamentos globais da estrutura treliçada em aço.

Neste trabalho de pesquisa são empregadas técnicas usuais de discretização, via método dos elementos finitos (MEF), por meio do programa ANSYS [1]. Os resultados obtidos ao longo desta investigação (deslocamentos, esforços e tensões) são confrontados e comparados, qualitativamente e quantitativamente, com os métodos usuais de mercado, de forma a obter resultados numéricos mais próximos do comportamento real desse tipo de sistema estrutural.

\section{ASPECTOS DE PROJETO E SITUAÇÃO DO ASSUNTO}

Devido à geometria modular do objeto em estudo, o aspecto de empregabilidade dos modelos estudados pode variar tanto no comprimento do vão livre, quanto no enrijecimento da seção resistente com a adição de novas linhas e ou configuração adequada para resistir aos esforços variados.

O sistema treliçado oferece soluções seguras e recomendadas para servir de escoramento de estruturas com grandes vãos livres submetidas a carregamentos elevados, sendo eficaz em leito de rios, passarelas de pedestres, passagem e acesso de viaturas, suporte de grandes vigas travessas e aduelas de pontes e viadutos. Sua utilização não se restringe ao escoramento do sistema estrutural envolvido, mas também à segurança e crescente necessidade de diminuição dos espaços hoje empregados nos canteiros de obra. Sua utilização em um elemento estrutural de altura elevada permite a liberação da área diretamente abaixo, garantindo segurança aos envolvidos na operação de construção, ganhos de área útil para armazenamento sem desprivilegiar o objetivo principal do instrumento, o escoramento da estrutura envolvida.

Ainda assim, outros aspectos relevantes podem ser citados como facilidade de transporte, armazenamento, resistência e baixo peso. A divisão em módulos do sistema estudado proporciona a possibilidade do emprego de contra flecha através de cunhas com dimensões variadas, controlando assim a deformação da estrutura envolvida.

A fragilidade deste sistema estrutural encontra-se em pontos críticos de projeto e execução. Visto a necessidade do emprego de respostas rápidas ao crescente e dinâmico mercado da construção civil, os projetistas veem-se forçados a conferir configurações e dimensionamentos das modulações, baseado em critérios simplificados como de uma viga bi apoiada 
simples, restringindo assim, o critério de dimensionamento econômico. A execução de montagem dos módulos contribui para a fragilidade do conjunto associada à falha humana na execução exigindo um aumento dos fatores de segurança utilizados.

Os critérios de verificação e definição dos carregamentos impostos à estrutura treliçada no mercado, não contemplam ponderações das ações seja no estado limite último (ELU) ou no estado limite de serviço (ELS). Corroborado com a necessidade de verificações e comparações com a norma de projeto, NBR 8800 [2], no que tange a ponderação dos carregamentos permanentes e variáveis.

\section{DESCRIÇÃO DOS MODELOS ESTRUTURAIS}

Os modelos estruturais investigados neste trabalho de pesquisa consistem de sistemas treliçados em aço, com 30 metros de comprimento, composto por módulos menores ligados entre si, através de parafusos de ligação nos seus banzos. No âmbito desta investigação, objetiva-se estudar o comportamento estrutural representativo do sistema de escoramento, tais como:

a) Modelo - I: duas linhas de treliças paralelas a 2 metros com 5 módulos intermediários de $6 \mathrm{~m}$ em cada linha, sistema de apoio na base da periferia do conjunto com poste de união dos banzos e contraventamento horizontal, em tubos com ligação rígida a cada 0,5 metros;

b) Modelo - II: duas linhas de treliças paralelas a 2 metros com 5 módulos intermediários de $6 \mathrm{~m}$ em cada linha, sistema de apoio na base da periferia do conjunto com poste de união dos banzos e contraventamento horizontal, em tubos com ligação rotulada a cada 0,5 metros.

No que diz respeito às características físicas do material aço, este possui módulo de elasticidade longitudinal igual a 2,10 x $10^{11} \mathrm{~N} / \mathrm{m}^{2}$, coeficiente de Poisson igual a 0,3 ( $\left.\mathrm{v}=0,3\right)$ e densidade de $7850 \mathrm{~kg} / \mathrm{m}^{3}$. Foram empregados aços comerciais como SAC-50, SAE 1040, SAE 5140 e SAE 1010 nos banzos, diagonais, prisioneiros e tubos de contraventamento, respectivamente.

\section{MODELAGEM COMPUTACIONAL}

Os modelos numéricos foram gerados usando técnicas usuais de discretização, via método dos elementos finitos (MEF). São empregadas técnicas usuais de discretização, por meio do emprego do programa ANSYS [1]. No presente modelo computacional, as estruturas de aços são simuladas por elementos finitos tridimensionais, onde são considerados os efeitos de flexão, esforços normais e tensões atuantes além dos deslocamentos globais. Os resultados obtidos são demonstrados e comparados com os limites recomendados em normas de projeto e sua utilização no mercado, no que tange aos carregamentos estáticos. 


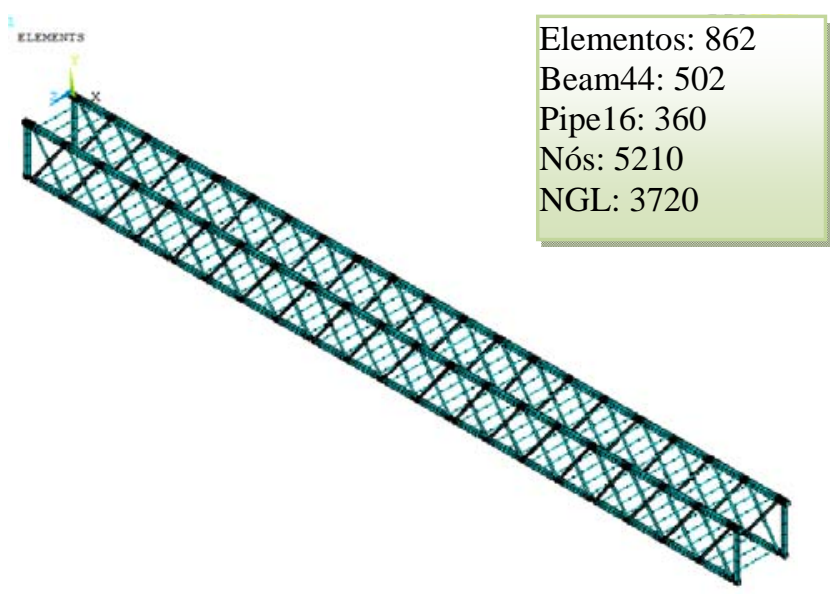

Figura 1. Modelo estrutural I.

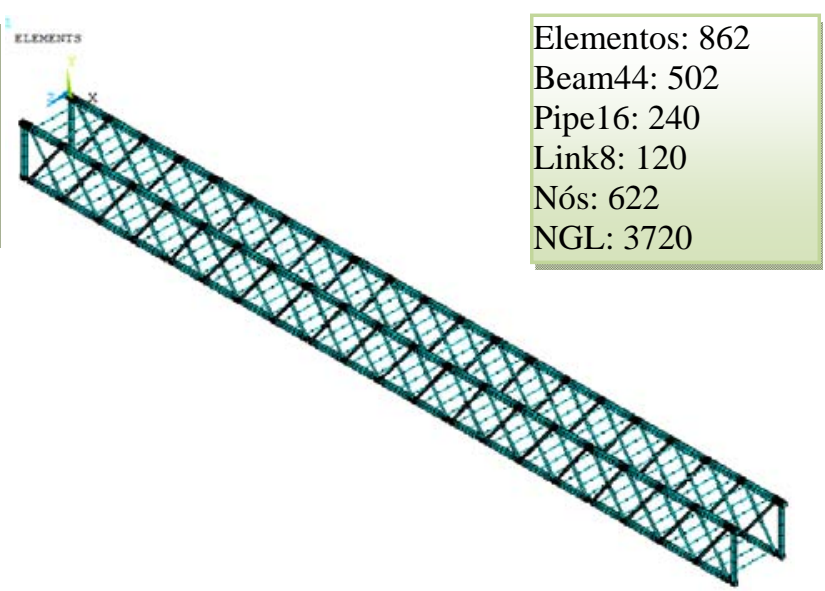

Figura 2. Modelo estrutural II.

Inicialmente, um modelo numérico-computacional bastante refinado foi desenvolvido onde os banzos, as diagonais e os travamentos são simulados por meio de elementos finitos refinados de viga 3D BEAM44, tubo 3D PIPE16 e tubos para travamento LINK8, respectivamente, presentes na biblioteca de elementos do ANSYS 12.0 [1]. Desta forma, o comportamento gerado pela interação entre os elementos estruturais (banzos, diagonais e travamento) foi obtido naturalmente.

O elemento BEAM44 [1], apresentado na Figura 3, possui seis graus de liberdade por nó, sendo três translações e três rotações nas direções x, y e z. Ele permite a utilização de diferentes geometrias nas extremidades opostas da barra. A orientação do elemento vai do nó I para o nó J, sendo esse eixo longitudinal, o eixo o x. Os eixos principais y e z estão localizados na seção transversal.

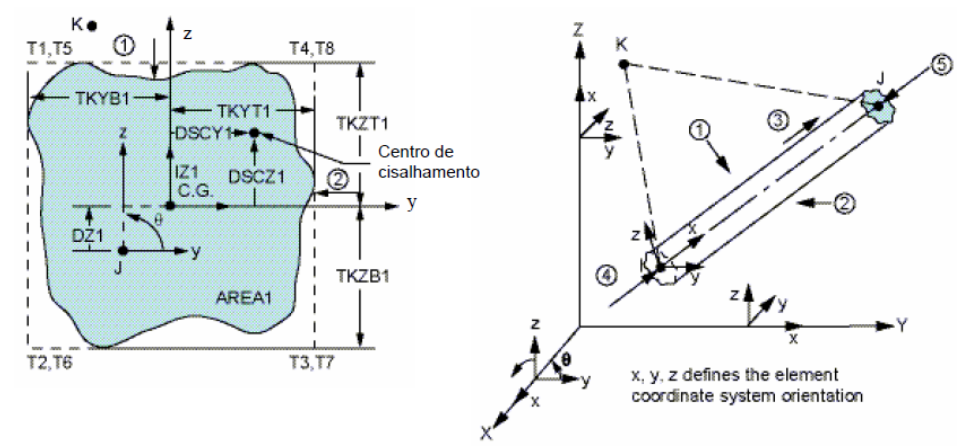

Figura 3. Elemento BEAM 44 ANSYS [1].

O elemento finito de tubo PIPE 16 [1] é caracterizado por seis graus de liberdade em cada nó: três translações e três rotações associadas aos eixos x, y, e z, respectivamente, como ilustrado na Figura 4. A orientação do elemento vai do nó I para o nó J, sendo esse eixo longitudinal, o eixo x. Os eixos principais y e z estão localizados na seção transversal.

O elemento finito de tubo LINK8 [1] é definido por apresentar três graus de liberdade em cada nó: elemento uniaxial de tensão de compressão com três translações associadas aos eixos x, y, e z, como ilustrado na Figura 5. A orientação do elemento vai do nó I para o nó J, sendo esse eixo longitudinal, o eixo x. Os eixos principais y e z estão localizados na seção transversal. 


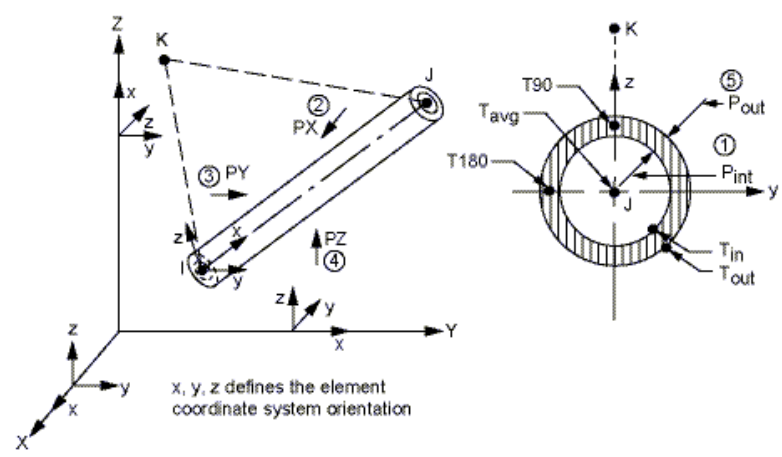

Figura 4. Elemento finito de tubo 3D PIPE16 ANSYS [1].
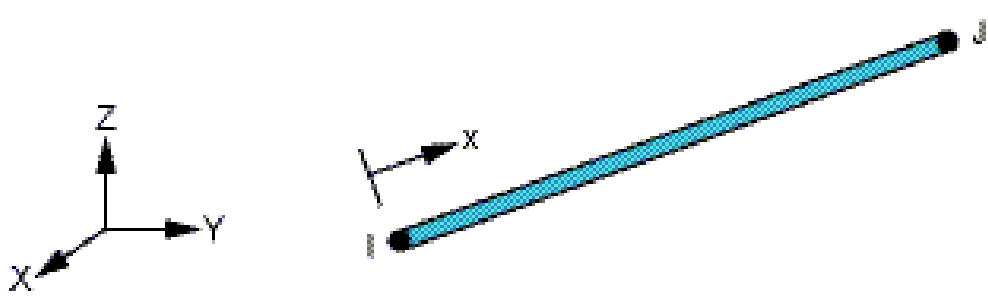

Figura 5. Elemento finito de tubo LINK8 ANSYS [1].

\section{VALIDACÃO DO MODELO NUMÉRICO DESENVOLVIDO}

Neste item são descritas resumidamente as análises realizadas com base na utilização do programa ANSYS [1], objetivando testar a eficiência e a confiabilidade dos modelos numéricos propostos, no que diz respeito ao estudo de estruturas treliçadas para o escoramento de elementos estruturais em aço e concreto.

A validação dos dois modelos numéricos desenvolvidos, ilustrados na Figura 1 e na Figura 2, respectivamente, foi feita comparando-se os valores máximos da resposta da estrutura, correspondentes aos deslocamentos translacionais verticais, obtidos de acordo com a presente metodologia de análise, em comparação com aqueles obtidos por normas. Ressalta-se que a comparação destes resultados revelou que os mesmo são absolutamente idênticos e, portanto, considerados satisfatórios.

Considerando-se as ações de cargas permanentes e variáveis, foram confrontadas as cargas provenientes do peso próprio da estrutura, sobrecargas de utilização e carga de vento, conforme as normas, ABNT NBR 8800 [2] e ABNT NBR 6120 [4].

\section{ANÁLISE LINEAR E DISCUSSÃO DOS RESULTADOS}

O objetivo central deste trabalho de pesquisa é verificar os métodos simplificados de projeto adotados atualmente na prática corrente de projeto, sobre a resposta estática (deslocamentos e esforços) de estruturas treliçadas para o escoramento de elementos estruturais. Para tal, emprega-se um modelo em elementos finitos onde foi realizada uma análise dos deslocamentos e os esforços máximos de projeto, comparando-se com o fator de segurança adotado na estrutura de escoramento. 
Conforme as análises a seguir, serão verificadas as diferenças do deslocamento vertical dos modelos apresentados e a indicação de adequação do método simplificado de projeto, a ponderação das cargas de projeto, tomando como base as normas descritas.

De acordo com o valor da flecha máxima estabelecida pela norma brasileira ABNT NBR 15696 [3], o deslocamento limite para elementos estruturais de escoramento apresenta um valor de aceitabilidade máximo de 1 + L/500, onde L corresponde ao vão máximo considerado.

\subsection{Modelo estrutural I: análise de deslocamentos e esforços}

Na sequência do estudo, a Figura 6 apresenta as curvas associadas aos deslocamentos verticais, obtidos no centro da estrutura treliçada, em função da variação do carregamento adicional de topo do modelo investigado. Assim sendo, para o vão de $30 \mathrm{~m}$, o deslocamento vertical máximo admissível correspondente ao modelo I é de $61 \mathrm{~mm}$. Conforme objeto de estudo, são incluídos os deslocamentos verticais máximos no centro do vão do elemento estrutural como modelo simplificado de projeto, que se constitui de carregamentos no estado limite de utilização (ELU) sem ponderação dos carregamentos. Na sequência ilustram-se os resultados obtidos no modelo numérico estudado sem ponderação das ações de cargas e curvas com as ponderações das cargas, no modelo simplificado de projeto e no modelo numérico estudado, comparadas no gráfico ilustrado na Figura 6.

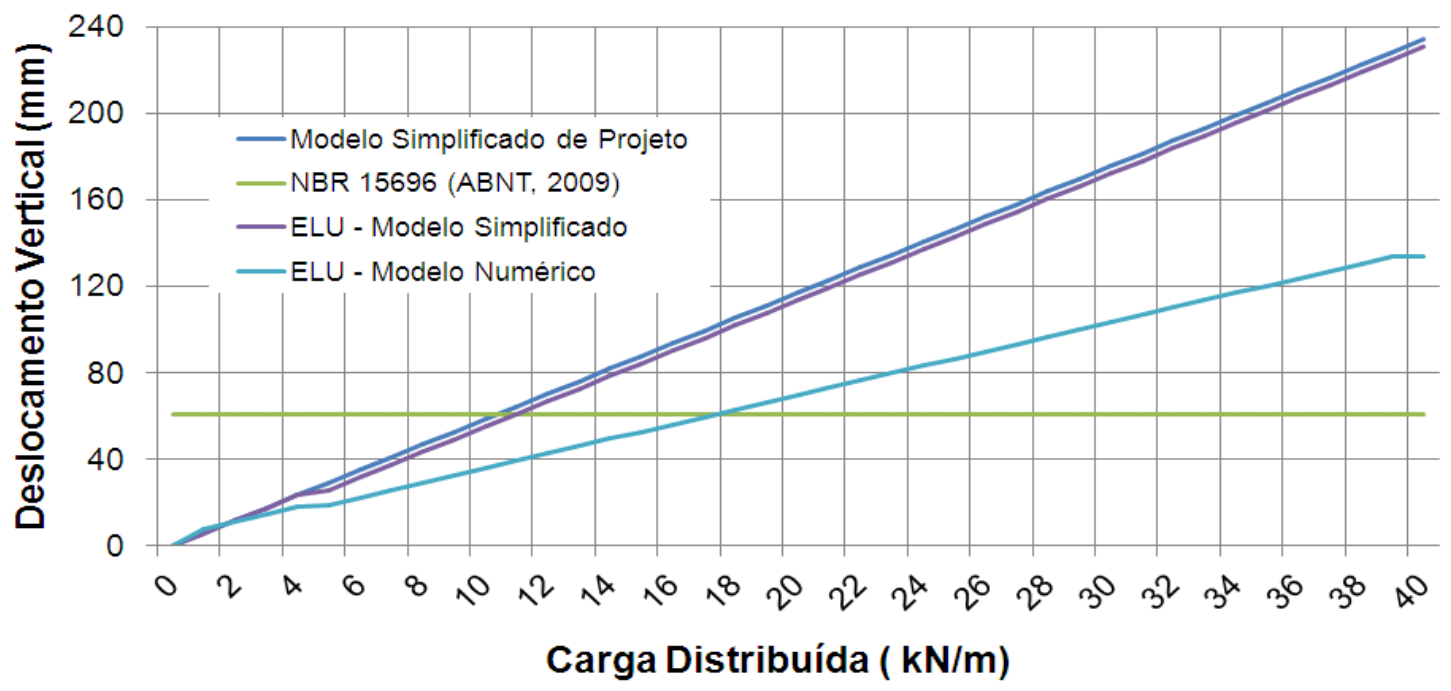

Figura 6. Variação do deslocamento vertical em função da carga distribuída no Modelo I.

Observando-se os valores apresentados na Figura 6, verifica-se uma variação linear dos valores máximos destes deslocamentos, onde o modelo simplificado de projeto atende ao proposto no tocante aos deslocamentos inferiores preconizados pela norma ABNT 15696 [3], até o limite de carregamento de aproximadamente $10,50 \mathrm{kN}$. O modelo numérico do ANSYS [1] apresenta uma diminuição considerável nos deslocamentos em função dos carregamentos solicitados, conforme verificado na Figura 6. O mesmo pode ser verificado na ponderação dos carregamentos (ELU) para o modelo simplificado de projeto e o modelo numérico estudado. 
Na análise de esforços atuantes no sistema estrutural treliçado desenvolvido no presente trabalho, observa-se uma redução no nível de esforços normais e tensões nas diagonais próximas aos apoios, principalmente nas diagonais extremas, mais propensas aos esforços provenientes da reação de apoio, novamente corroborando com a aceitação de aproximação dos esforços cortantes de uma viga simples e bi apoiada, adotada no modelo simplificado de projeto. Todos os resultados podem ser verificados na Tabela 1 e a deformada da estrutura na Figura 7, onde são confrontados os deslocamentos verticais (eixo y) nos modelos: Simplificado de projeto, Numérico, ELU - Simplificado de projeto e ELU - Numérico.

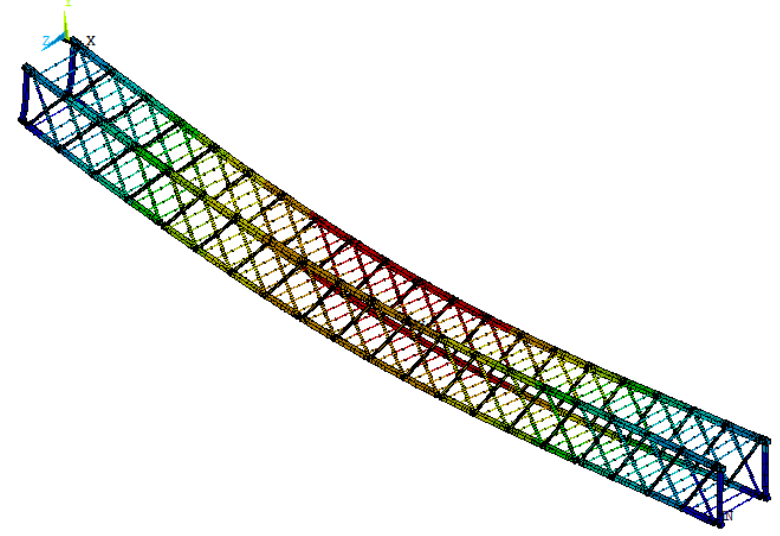

Figura 7. Deformada do Modelo estrutural I.

Tabela 1. Deslocamento vertical em função da carga distribuída no Modelo I

\begin{tabular}{cccc}
\hline \multirow{2}{*}{$\begin{array}{c}\text { Carga } \\
\text { Distribuída } \\
\text { q (N/m) }\end{array}$} & $\begin{array}{c}\text { Dodelo Simplificado de } \\
\text { Projeto: sem ponderação } \\
\text { do carregamento }\end{array}$ & $\begin{array}{c}\text { Modelo Simplificado de } \\
\text { Projeto: com pondera- } \\
\text { ção do carregamento }\end{array}$ & $\begin{array}{c}\text { Modelo em Elementos } \\
\text { Finitos: com ponderação } \\
\text { do carregamento }\end{array}$ \\
\hline 1 & 5,62 & 5,62 & 7,60 \\
5 & 28,11 & 24,90 & 18,37 \\
10 & 56,22 & 53,00 & 35,04 \\
15 & 84,32 & 81,11 & 51,54 \\
20 & 112,43 & 109,22 & 68,00 \\
25 & 140,54 & 137,33 & 84,45 \\
30 & 168,65 & 165,43 & 100,88 \\
35 & 196,75 & 193,54 & 117,31 \\
40 & 224,86 & 221,65 & 133,74 \\
\hline
\end{tabular}

\subsection{Modelo estrutural II: análise de deslocamentos e esforços}

Na sequência do estudo, a Figura 8 apresenta as curvas associadas aos deslocamentos verticais, obtidos no centro da estrutura treliçada, em função da variação do carregamento adicional de topo do modelo investigado. Assim sendo, para o vão de $30 \mathrm{~m}$, o deslocamento vertical máximo admissível correspondente ao modelo II é de $61 \mathrm{~mm}$. Conforme objeto de 
estudo, são incluídos os deslocamentos verticais máximos no centro do vão do elemento estrutural como modelo simplificado de projeto, que se constitui de carregamentos no estado limite de utilização (ELU) sem ponderação dos carregamentos. Na sequência, apresentam-se os resultados do modelo numérico estudado sem ponderação das ações de cargas e curvas com as ponderações das cargas, no modelo simplificado de projeto e no modelo numérico estudado, de acordo com a Figura 8.

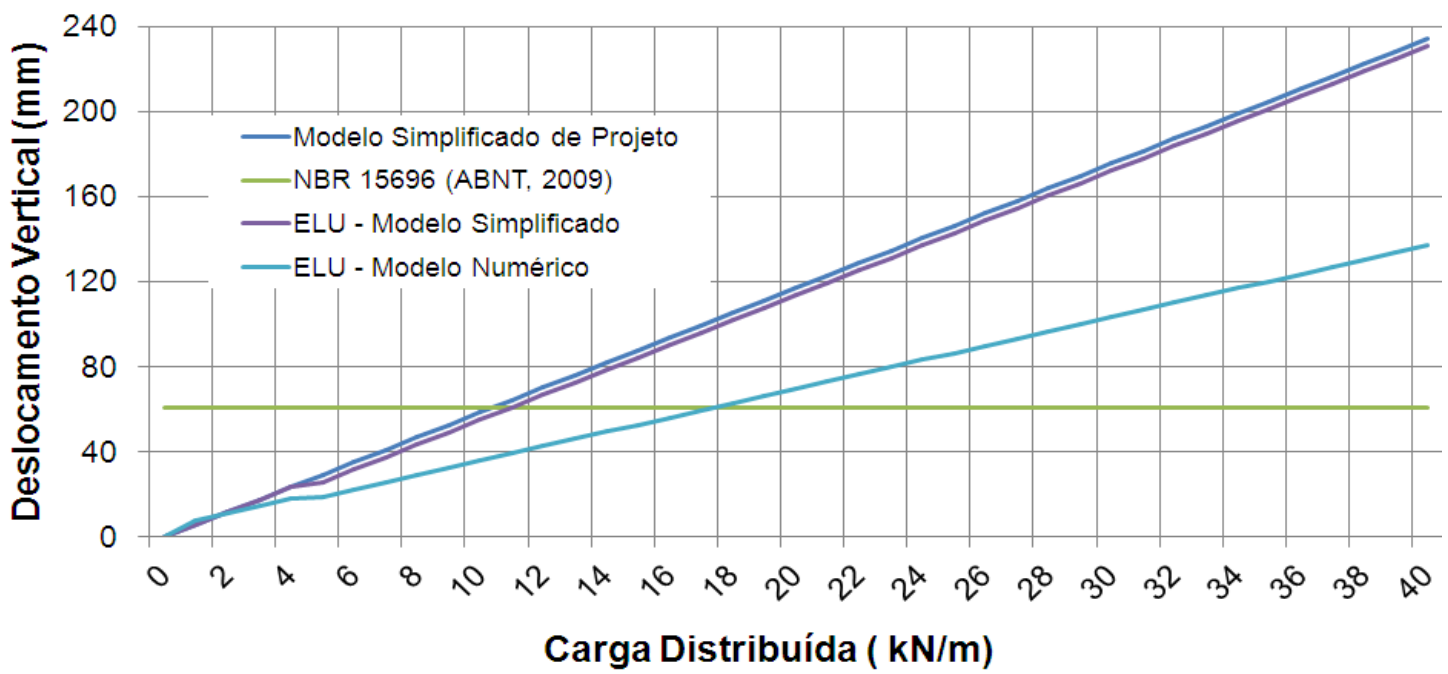

Figura 8. Variação do deslocamento vertical em função da carga distribuída no Modelo II.

A Figura 8 apresenta as curvas dos deslocamentos verticais máximos do Modelo II. Basicamente, observa-se uma variação linear dos valores máximos destes deslocamentos, onde o modelo simplificado de projeto atende ao proposto no tocante aos deslocamentos inferiores preconizados pela norma ABNT 15696 [3], até o limite de carregamento de aproximadamente 10,50kN. O modelo numérico do ANSYS [1] apresenta uma diminuição considerável nos deslocamentos em função dos carregamentos atuantes, conforme verificado na Figura 8. O mesmo pode ser verificado na ponderação dos carregamentos (ELU) para o modelo simplificado de projeto e o modelo numérico estudado. Todos os resultados podem ser verificados na Tabela 2 e a deformada da estrutura na Figura 9, onde são confrontados os deslocamentos verticais (eixo y) nos modelos: Simplificado de projeto, Numérico, ELU - Simplificado de projeto e ELU - Numérico.

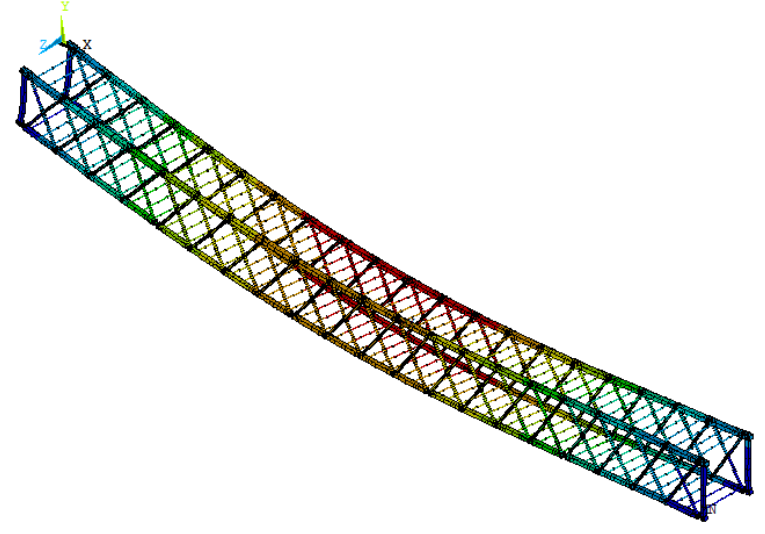

Figura 9. Deformada do Modelo estrutural II. 
Tabela 2. Deslocamento vertical em função da carga distribuída no Modelo II

\begin{tabular}{cccc}
\hline \multirow{2}{*}{$\begin{array}{c}\text { Carga } \\
\text { Distribuída } \\
\text { q (kN/m) }\end{array}$} & $\begin{array}{c}\text { Modelo Simplificado de } \\
\text { Projeto: sem ponderação } \\
\text { do carregamento }\end{array}$ & $\begin{array}{c}\text { Modelo Simplificado de } \\
\text { Projeto: com pondera- } \\
\text { ção do carregamento }\end{array}$ & $\begin{array}{c}\text { Modelo em Elementos } \\
\text { Finitos: com ponderação } \\
\text { do carregamento }\end{array}$ \\
\hline 1 & 5,85 & 5,85 & 7,49 \\
5 & 29,25 & 25,91 & 18,55 \\
10 & 58,50 & 55,16 & 35,61 \\
15 & 87,75 & 84,41 & 52,52 \\
20 & 117,00 & 113,65 & 69,38 \\
25 & 146,24 & 142,90 & 86,23 \\
30 & 175,49 & 172,15 & 103,07 \\
35 & 204,74 & 201,40 & 119,91 \\
40 & 233,99 & 230,65 & 133,42 \\
\hline
\end{tabular}

Novamente, conforme verificado no modelo anterior, na análise de esforços atuantes no sistema estrutural treliçado desenvolvido no presente trabalho, observa-se uma redução no nível de esforços normais e tensões nas diagonais próximas aos apoios, principalmente nas diagonais extremas, mais propensas aos esforços provenientes da reação de apoio, novamente corroborando com a aceitação de aproximação dos esforços cortantes de uma viga simples e bi apoiada, adotada no modelo simplificado de projeto.

\section{ANÁLISE NÃO LINEAR E DISCUSSÃO DOS RESULTADOS}

\subsection{Modelo estrutural I: análise de deslocamentos e esforços}

Na sequência do estudo, a Figura 10 apresenta as curvas associadas aos deslocamentos verticais, obtidos no centro da estrutura treliçada, em função da variação do carregamento adicional de topo do modelo investigado. Assim sendo, para o vão de $30 \mathrm{~m}$, o deslocamento vertical máximo admissível correspondente ao modelo I é de 61mm.

Conforme objeto de estudo, são incluídos os deslocamentos verticais máximos no centro do vão do elemento estrutural como modelo simplificado de projeto, que se constitui de carregamentos no estado limite de utilização (ELU) sem ponderação dos mesmos. Na sequência são apresentados os resultados obtidos com o modelo numérico sem ponderação das ações de cargas e curvas com as análises lineares e não lineares, no modelo simplificado de projeto e no modelo numérico estudado, comparados no gráfico ilustrado na Figura 10.

Observando-se a Figura 10 verifica-se uma variação linear dos valores máximos destes deslocamentos, onde o modelo simplificado de projeto atende ao proposto no tocante aos deslocamentos inferiores preconizados pela norma ABNT NBR 15696 [3], até o limite de carregamento de aproximadamente 203kN. O modelo numérico da análise linear do ANSYS [1] apresenta uma diminuição considerável nos deslocamentos em função dos carregamentos so- 
licitados, proporcionando um aumento considerável na resistência do conjunto, com carregamentos de aproximadamente 304,6kN, conforme verificado na Figura 10. Da mesma forma, verifica-se que o mesmo ocorre no modelo numérico da análise não linear, onde os valores dos deslocamentos máximos são inferiores ao do modelo simplificado de projeto.

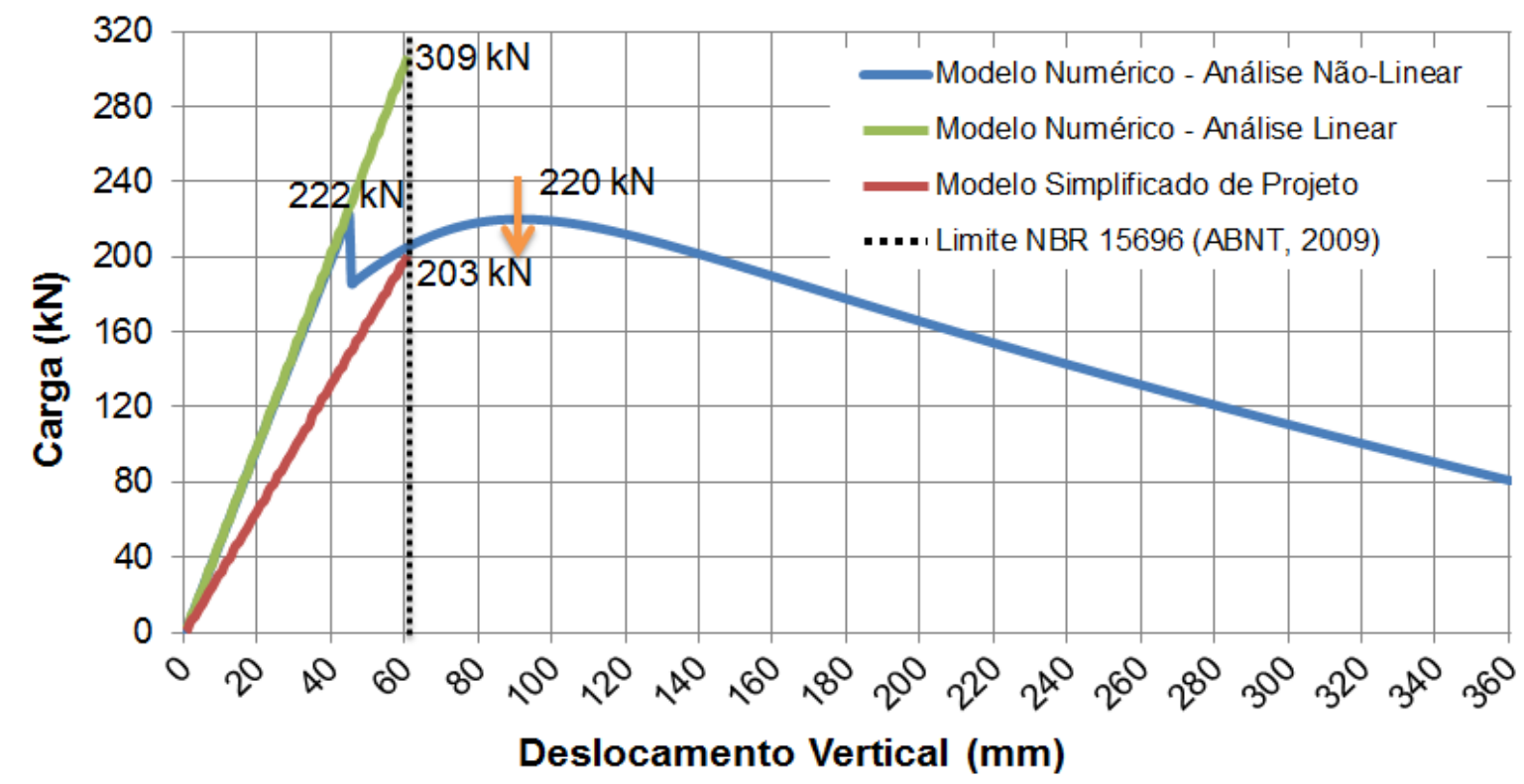

Figura 10. Variação do deslocamento vertical em função da carga concentrada no Modelo I.

Avaliando o modelo numérico de análise não linear, observa-se um comportamento elasto-plástico a partir do limite de carregamento de aproximadamente 222,8kN, configurando a formação de uma rótula plástica nos tubos de contraventamento mais próximos a extremidade do conjunto e posterior redistribuição dos esforços com o aparecimento de uma curva que tem o início de diminuição do carregamento aplicado a partir do valor aproximado de $220,07 \mathrm{kN}$. Todos os resultados podem ser verificados na Tabela 3 e a deformada da estrutura na Figura 11, onde são confrontados os deslocamentos verticais (eixo y) nos modelos: Simplificado de projeto, Numérico, ELU - Análise não linear e ELU - Análise Linear.
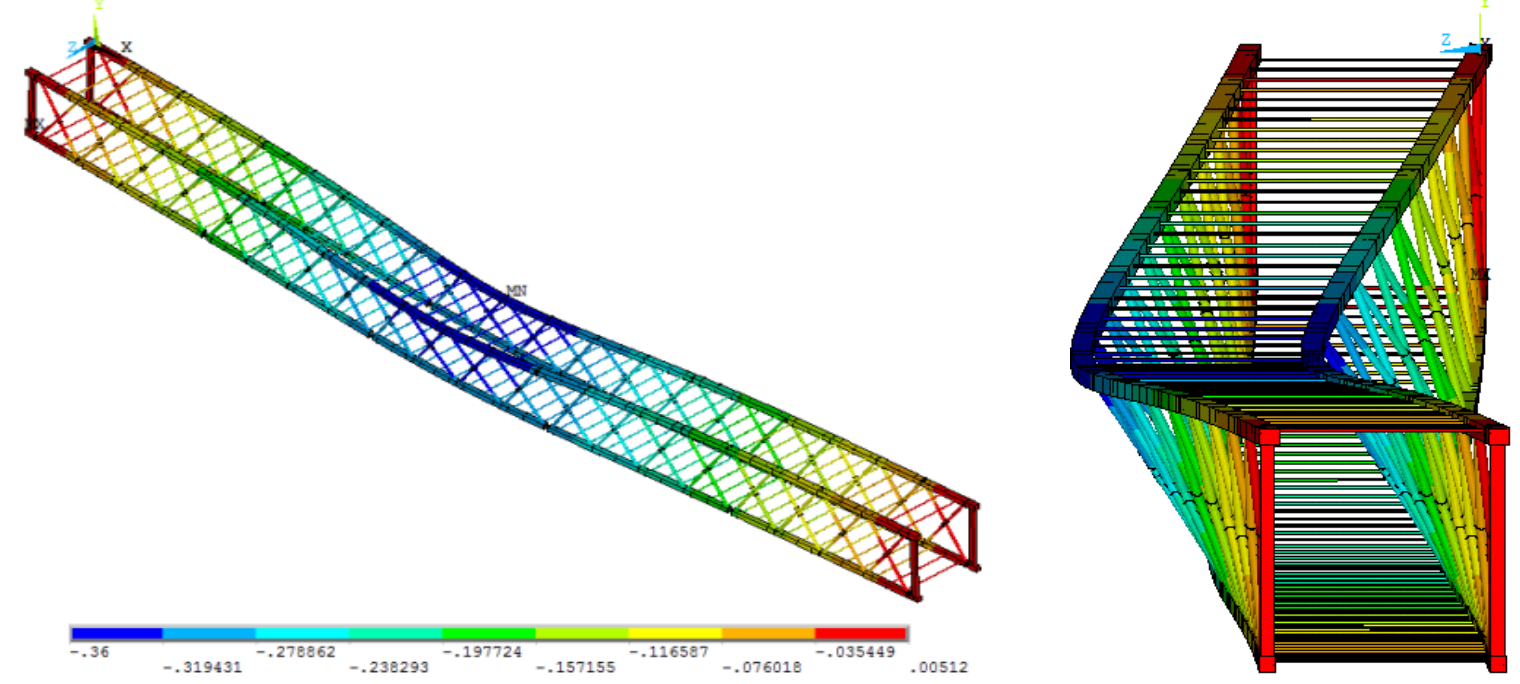

Figura 11. Deformada do Modelo estrutural I. 
Tabela 3. Deslocamento vertical em função da carga concentrada no Modelo I

\begin{tabular}{cccc}
\hline \multirow{2}{*}{$\begin{array}{c}\text { Carga } \\
\text { q }(\mathrm{kN})\end{array}$} & \multicolumn{3}{c}{ Deslocamento Translacional Vertical Máximo (mm) } \\
\cline { 2 - 4 } & $\begin{array}{c}\text { ELU - Modelo Numéri- } \\
\text { co Análise Não linear }\end{array}$ & $\begin{array}{c}\text { Modelo Simplificado de } \\
\text { Projeto }\end{array}$ & $\begin{array}{c}\text { ELU - Modelo Numéri- } \\
\text { co Análise Linear }\end{array}$ \\
\hline 1 & 0,19 & 0,30 & 0,19 \\
25 & 4,81 & 7,50 & 4,80 \\
50 & 9,64 & 14,99 & 9,60 \\
75 & 14,50 & 22,49 & 14,40 \\
100 & 19,37 & 29,98 & 19,20 \\
125 & 24,26 & 37,48 & 24,00 \\
150 & 29,18 & 44,97 & 28,80 \\
175 & 34,12 & 52,47 & 33,60 \\
200 & 39,07 & 59,96 & 38,40 \\
225 & 86,85 & 67,48 & 43,20 \\
250 & - & 74,95 & 48,00 \\
\hline
\end{tabular}

\subsection{Modelo estrutural II: análise de deslocamentos e esforços}

Na sequência do estudo, a Figura 12 ilustra curvas associadas aos deslocamentos verticais, obtidos no centro da estrutura treliçada, em função da variação do carregamento adicional de topo do modelo investigado. Assim sendo, para o vão de 30m o deslocamento vertical máximo admissível correspondente ao modelo II é de 61mm.

Conforme objeto de estudo, são incluídos os deslocamentos verticais máximos no centro do vão do elemento estrutural como modelo simplificado de projeto, que se constitui de carregamentos no estado limite de utilização (ELU) sem ponderação dos carregamentos. Na sequência são apresentados os resultados do modelo numérico sem ponderação das ações de cargas e curvas com as análises lineares e não lineares, no modelo simplificado de projeto e no modelo numérico estudado, confrontadas no gráfico apresentado na Figura 12.

Observando-se a Figura 12 verifica-se uma variação linear dos valores máximos destes deslocamentos, onde o modelo simplificado de projeto atende ao proposto no tocante aos deslocamentos inferiores preconizados pela norma ABNT NBR 15696 [3], até o limite de carregamento de aproximadamente 203kN. O modelo numérico de análise linear do ANSYS [1] apresenta uma diminuição considerável nos deslocamentos em função dos carregamentos atuantes, proporcionando um aumento considerável na resistência do conjunto, com carregamentos de aproximadamente $307 \mathrm{kN}$, conforme verificado na Figura 12. Da mesma forma, pode-se verificar que o mesmo ocorre no modelo numérico de análise não linear, onde os valores dos deslocamentos máximos são inferiores aos do modelo simplificado de projeto.

Avaliando-se o modelo numérico de análise não linear, observa-se um comportamento elasto-plástico a partir do limite de carregamento de aproximadamente $179 \mathrm{kN}$, configurando a formação de uma rótula plástica no prisioneiro mais próximo da extremidade do conjunto e posterior redistribuição dos esforços com o aparecimento de uma curva que tem o início de perda de carga a partir do limite de carregamento aproximado de $312 \mathrm{kN}$. Todos os resultados 
podem ser verificados na Tabela 4 e a deformada da estrutura na Figura 13, onde são confrontados os deslocamentos verticais (eixo y) nos modelos: Simplificado de projeto, Numérico, ELU - Análise não linear e ELU - Analise Linear.

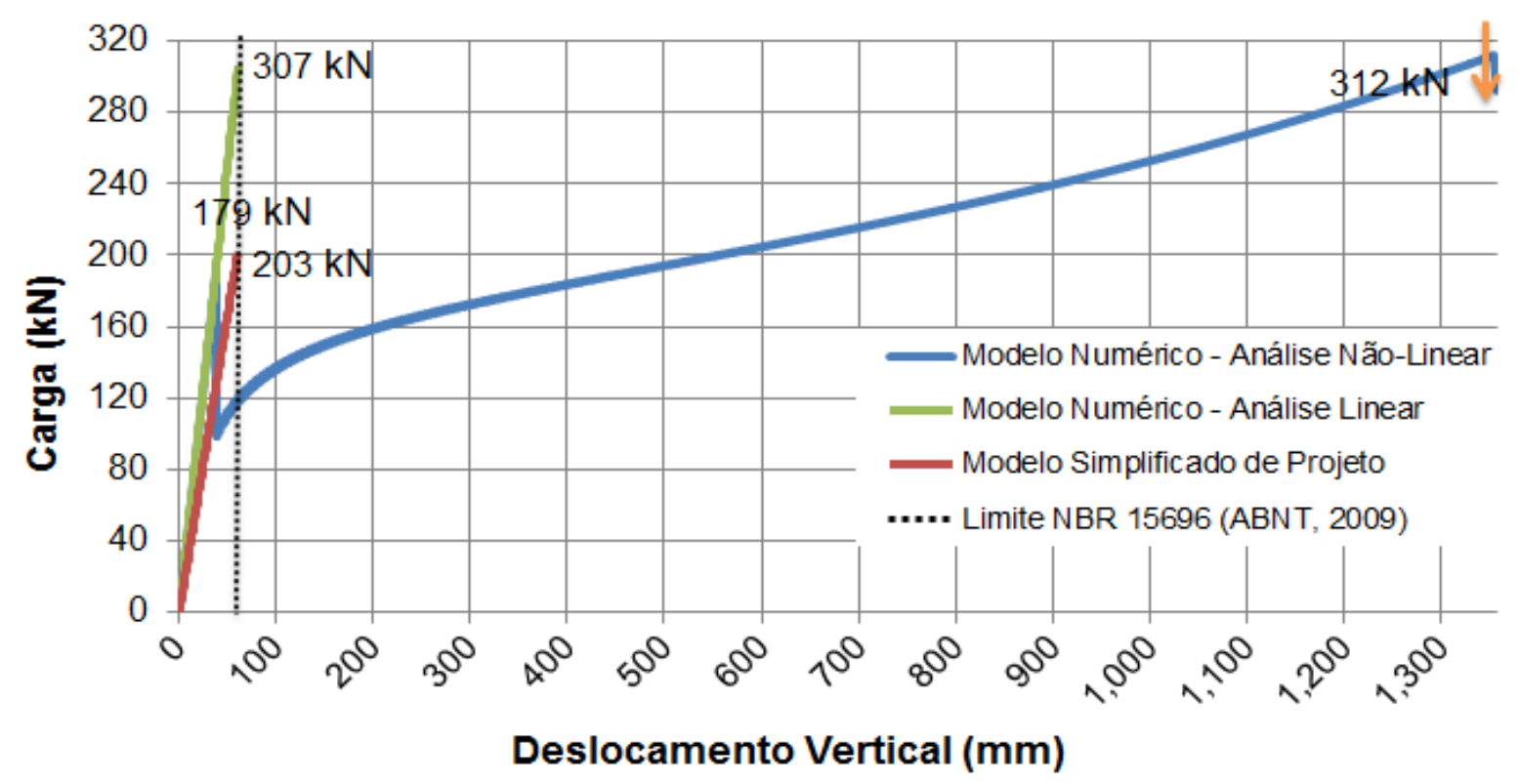

Figura 12. Variação do deslocamento vertical em função da carga concentrada no Modelo II.
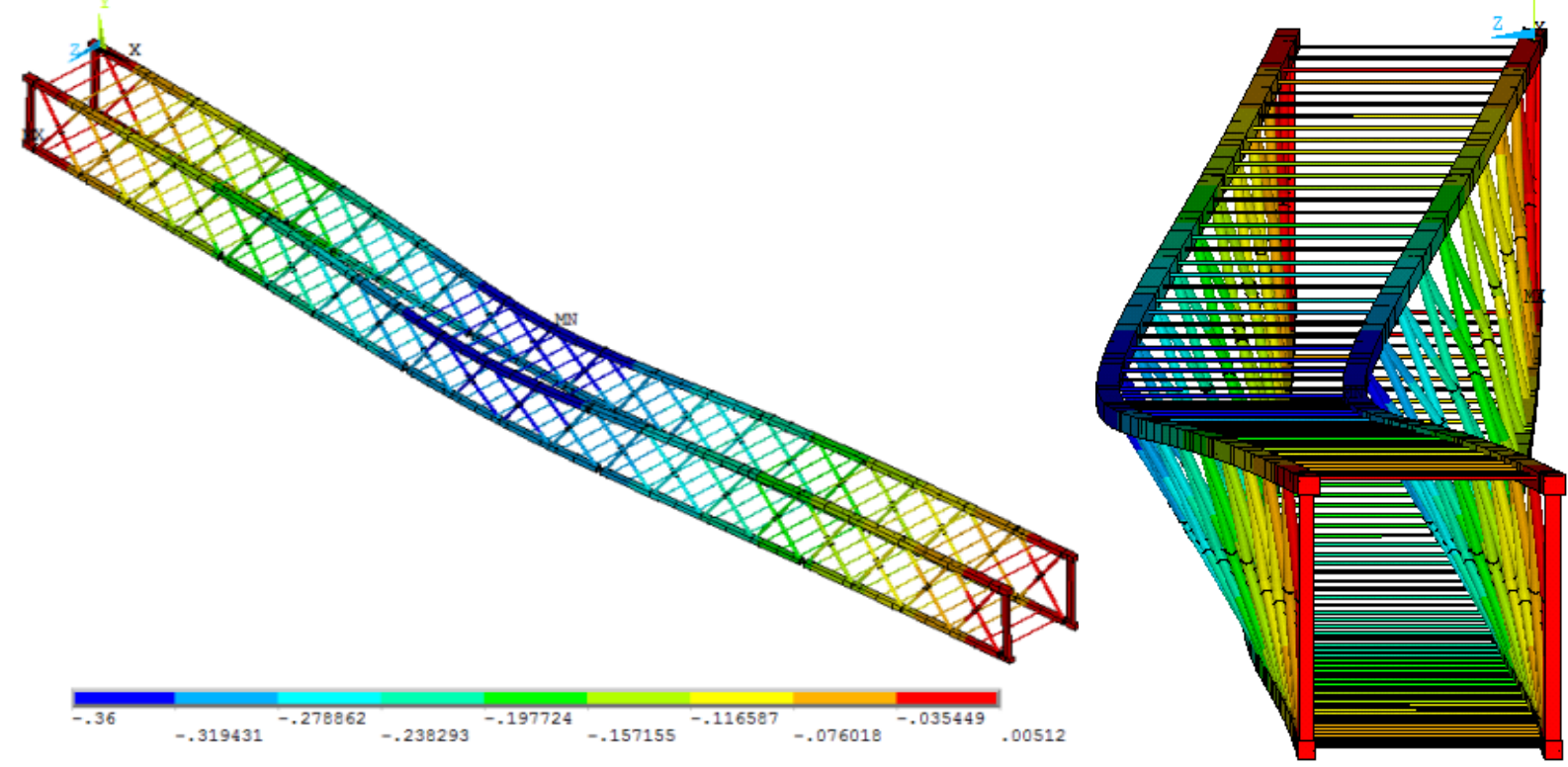

Figura 13. Deformada do Modelo estrutural II.

Novamente, conforme verificado no modelo anterior, na análise de esforços atuantes no sistema estrutural treliçado desenvolvido no presente trabalho, observa-se uma redução no nível de esforços normais e tensões nas diagonais próximas aos apoios, principalmente nas diagonais extremas, mais propensas aos esforços provenientes da reação de apoio, novamente corroborando com a aceitação de aproximação dos esforços cortantes de uma viga simples e bi apoiada, adotada no modelo simplificado de projeto. 
Tabela 4. Deslocamento vertical em função da carga concentrada no Modelo II

\begin{tabular}{cccc}
\hline $\begin{array}{c}\text { Carga } \\
\text { Concentrada } \\
\text { q }(\mathrm{kN})\end{array}$ & \multicolumn{3}{c}{ Deslocamento Translacional Vertical Máximo (mm) } \\
\cline { 2 - 4 } & $\begin{array}{c}\text { ELU - Modelo Numéri- } \\
\text { co Análise Não linear }\end{array}$ & $\begin{array}{c}\text { Modelo Simplificado de } \\
\text { Projeto }\end{array}$ & $\begin{array}{c}\text { ELU - Modelo Numéri- } \\
\text { co Análise Linear }\end{array}$ \\
\hline 1 & 0,20 & 0,30 & 0,20 \\
25 & 4,92 & 7,50 & 4,93 \\
50 & 9,87 & 14,99 & 9,85 \\
75 & 14,83 & 22,49 & 14,78 \\
100 & 19,81 & 29,98 & 19,70 \\
125 & 24,82 & 37,48 & 24,63 \\
150 & 29,85 & 44,97 & 29,55 \\
175 & 34,89 & 52,47 & 34,48 \\
200 & 39,97 & 59,96 & 39,40 \\
225 & - & 67,48 & 44,33 \\
250 & - & 74,95 & 49,25 \\
\hline
\end{tabular}

\section{ANÁLISE CONJUNTA DOS MODELOS INVESTIGADOS}

Devido à geometria especial da estrutura espacial treliçada, a mesma estará sujeita a instabilidade longitudinal, ou seja, a região comprimida ao longo do comprimento da treliça pode ser analisada como uma coluna, submetida a esforços de compressão. Sendo assim, para boa técnica empregada, faz-se necessária a utilização de contraventamento lateral do sistema treliçado com tubos. Nos modelos investigados neste trabalho de pesquisa, efetuou-se a verificação dos deslocamentos máximos no eixo de menor inércia do conjunto, (eixo z), de acordo com os resultados apresentados na Tabela 5.

Tabela 5. Comparação entre os deslocamentos verticais máximos

\begin{tabular}{cccccc}
\hline \multicolumn{2}{c}{ Análise Linear dos Modelos } & \multicolumn{2}{c}{ Análise Não Linear dos Modelos } \\
\hline $\begin{array}{c}\text { Carga } \\
\text { Distribuída }(\mathrm{kN} / \mathrm{m})\end{array}$ & $\begin{array}{c}\text { Modelo I } \\
(\mathrm{mm})\end{array}$ & $\begin{array}{c}\text { Modelo II } \\
(\mathrm{mm})\end{array}$ & $\begin{array}{c}\text { Carga } \\
\text { Concentrada }(\mathrm{kN})\end{array}$ & $\begin{array}{c}\text { Modelo I } \\
(\mathrm{mm})\end{array}$ & $\begin{array}{c}\text { Modelo II } \\
(\mathrm{mm})\end{array}$ \\
\hline 1 & 5,62 & 5,85 & 1 & 0,19 & 0,20 \\
5 & 28,11 & 29,25 & 25 & 4,81 & 4,92 \\
10 & 56,22 & 58,50 & 50 & 9,64 & 9,87 \\
15 & 84,32 & 87,75 & 75 & 14,50 & 14,83 \\
20 & 112,43 & 117,00 & 100 & 19,37 & 19,81 \\
25 & 140,54 & 146,24 & 125 & 24,26 & 24,82 \\
30 & 168,65 & 175,49 & 150 & 29,18 & 29,85 \\
35 & 196,75 & 204,74 & 175 & 34,12 & 34,89 \\
40 & 224,86 & 233,99 & 200 & 39,07 & 39,97 \\
\hline
\end{tabular}


Na análise dos resultados, verifica-se a redução dos deslocamentos verticais em função do aumento do contraventamento, ou seja, a inclusão de contraventamento a cada $0,50 \mathrm{~m}$ oferece uma significativa redução dos deslocamentos verticais. Tal fato deve-se ao acréscimo de enrijecimento à estrutura com a adição de tubos de contraventamento a cada 0,50m.

\section{CONSIDERAÇÕES FINAIS}

Neste trabalho de pesquisa foi desenvolvido um estudo, onde o objetivo central foi o de verificar e confrontar os resultados obtidos a partir da utilização de uma metodologia de análise, baseada em um modelo simplificado de projeto [5], com aquela respaldada pelo desenvolvimento de modelos mais complexos, desenvolvidos com base no emprego de técnicas usuais de discretização, via método dos elementos finitos (MEF), por meio do programa ANSYS [1], no que diz respeito à avaliação estrutural da resposta estática linear e não linear (deslocamentos e esforços) de sistemas espaciais treliçados.

Os resultados obtidos com base na utilização do modelo simplificado de projeto [5] são respaldados pelo emprego da norma ABNT NBR 8800 [2], pelo fato de que a mesma considera o comportamento de elementos estruturais constituídos de aço. Por outro lado, os resultados do presente estudo revelam que o modelo simplificado de projeto é bastante conservativo quando comparado aos modelos numéricos mais refinados, desenvolvidos nesta investigação. Existem diferenças quantitativas significativas, associadas à resposta estrutural dos modelos (deslocamentos e esforços) investigados, quando estas metodologias são confrontadas.

Este fato é relevante para a obtenção dos deslocamentos e esforços; e, bem como, para uma avaliação mais apropriada dos carregamentos permanentes e variáveis, com base nas devidas ponderações da norma ABNT NBR 8800 [2], objetivando maximizar a utilização econômica destes sistemas estruturais espaciais treliçados utilizados correntemente para o escoramento de estruturas civis.

\section{Agradecimentos}

Os autores agradecem ao suporte financeiro fornecido pelas Agências de Fomento à Pesquisa do país, CAPES, CNPq e FAPERJ, que possibilitaram a realização deste trabalho de pesquisa.

\section{REFERÊNCIAS}

[1] ANSYS. Swanson Analysis Systems, Inc., P.O. Box 65, Johnson Road, Houston, PA, 15342-0065, version 12.1, Basic analysis procedures, Second edition, 2009.

[2] NBR 8800: Projeto de Estruturas de Aço e de Estruturas Mistas de Aço e Concreto de Edifícios - Procedimento. Associação Brasileira de Normas Técnicas, ABNT, 2008.

[3] NBR 15696: Formas e Escoramento para Estruturas de Concreto. Projeto, Dimensionamento e Procedimentos Executivos. Associação Brasileira de Normas Técnicas, ABNT, 2009. 
[4] NBR 6120: Cargas para o Cálculo de Estruturas de Edificações. Associação Brasileira de Normas Técnicas, ABNT, 1980.

[5] Ary, Jose Luiz, Projetos e cálculos para treinamento e técnicas e equipamentos. Mills Estruturas e Serviços de Engenharia. 